\title{
Association between radiological findings and total and regional function in emphysema
}

\author{
JEAN R. NAIRN, F. J. PRIME, AND G. SIMON \\ From the Institute of Diseases of the Chest and the Brompton Hospital, London
}

\begin{abstract}
Tests of overall and regional lung function using xenon-133 with fixed counters were carried out on 49 patients who were judged on specified radiological grounds to have emphysema: 31 of them also had clinical evidence of chronic bronchitis. The radiological extent of the disease was classified as generalized, extensive localized or localized. The results of the tests were compared with the radiographic extent of the disease and with the local radiographic appearances. Derangements of total lung function agreed well with the radiological extent of the disease ; in particular, the average level of $\mathrm{PaCO}_{2}$ was lower than that predicted from the F.E.V.1 when generalized and extensive localized emphysema were present. Co-existing chronic bronchitis was associated with higher levels of $\mathrm{PaCO}_{2}$. The resting $\mathrm{PaO}_{2}$ was higher if one or both lower regions were normally ventilated despite unevenness of ventilation elsewhere, emphasizing the importance of the lower lung regions in determining the overall V/Q of the lungs. Regional derangements of ventilation coincided fairly well with the radiographic distribution of vascular narrowing or loss but the blood flow was found to be diminished in less than $5 \%$ of upper and middle regions with radiological changes. Ventilation was impaired in parts of the lungs where the vascular shadows were apparently normal. This finding was attributed to the effects of chronic bronchitis, because it was also found in seven patients with this disease who did not have radiographic evidence of emphysema ; in these, impairment of ventilation in the middle and lower regions was a salient feature.
\end{abstract}

At the Ciba Symposium held in 1959, the contributors agreed that pulmonary emphysema should be defined in terms of its morbid anatomy and that the diagnosis should not be made during life unless there was good reason to believe that these changes were actually present. Since then the morbid anatomical studies carried out by Reid and Simon (1959), Laws and Heard (1962), and Reid and Millard (1964) have shown that, when emphysema is sufficiently severe and widespread, it can be detected during life from radiographs of the lungs. In particular, Reid and Millard found that when the radiological criteria proposed by Simon (1964) were fulfilled, more than half the area of a sagittal slice of the lung cut through the hilum was occupied by emphysematous changes of the panacinar type (graded 3 and 4 in severity in their classification). When vessel narrowing and vessel loss in the radiograph were present in only a particular region, morbid anatomical changes of panacinar emphysema grade 3 and 4 were found in the corresponding part of the lung.

In this paper we report measurements of regional and total lung function in patients who present some or all of the radiological appearances? of emphysema (as defined by Simon (1964) and $₹$ expanded in the appendix), in order to study the $\frac{\mathrm{O}}{\mathrm{v}}$ relationships between radiological appearances, $x$ regional and total lung function, and presumed $\frac{3}{3}$ panacinar emphysema.

The recent painstaking studies on patients with chronic airways obstruction (Fletcher, HughJones, McNicol, and Pride, 1963 ; Nash, Briscoe, 은 and Cournand, 1965; Thurlbeck, Fraser, and $D$ Bates, 1965 ; Burrows, Fletcher, Heard, Jones, and을. Wootliff, 1966) have been concerned with relating N the symptoms, signs, radiological appearance, and function of the lungs in different groups of 0 patients with airways obstruction during life to $N$ the frequency and extent of pulmonary emphysema found at necropsy. In none of these paperso was there any attempt to relate the observed distribution of radiological change to the topo-? graphical changes seen on the radiograph by using tests of regional lung function.

By careful measurement and use of elaborate radiographic methods, several authors have found $\mathbb{Q}$ a fairly close linear correlation between 'radio- $\overline{0}$ 
logical chest volume' and total lung capacity (Hurtado and Fray, 1933 ; Aslett, Hart, and McMichael, 1939 ; Barnhard, Pierce, Joyce, and Bates, 1960). Wade and Gilson (1951) and Wade (1954) have made a detailed comparison between the movements of the diaphragm and the subdivisions of vital capacity. Here we give simple measurements of the radiographic appearance and, where these were not feasible, descriptions which were as far as possible objective (see Appendix), and we have correlated these with observed functional defects. We hope this may help the physician and the radiologist to estimate the effects on funotion of radiographic abnormalities.

Uncomplicated chronic bronchitis does not present any distinctive radiological features, but since it may cause severe chronic irreversible airways obstruction (Medical Research Council, 1965), we have noted those of our patients with radiological evidence of emphysema who also had clinical evidence of chronic bronchitis.

We have avoided defining emphysema in functional terms; our findings apply only to patients whose radiographic appearances indicate the presence of panacinar emphysema grade 3 or 4 (Reid and Millard, 1964).

\section{SELECTION OF PATIENTS}

The forty-nine patients ( 4 female and 45 male) selected had radiological evidence of local or widespread emphysema, whether or not they had shortness of breath on exertion. Patients whose only evidence of emphysema was a single well-demarcated avascular area on the chest radiograph were excluded.

A further seven patients were studied who had none of the radiological signs of emphysema. In particular, the position and shape of the diaphragm and the vascular pattern of the lungs were normal. Each had a long history of productive cough and had severe airways obstruction (F.E.V.1 1.5 litres or less). We considered that they suffered from severe chronic obstructive bronchitis (Medical Research Council, 1965 ) in the absence of gross panacinar emphysema and we wished to study the possible effects of chronic bronchitis on regional lung function.

\section{METHODS OF STUDY}

CLINICAL The clinical history of each patient and the assessment of his symptoms was noted using the pro forma recommended by the Questionnaire on respiratory symptoms of the Medical Research Council (1960). The height and weight of each patient were recorded together with the findings on clinical examination. The diagnosis of chronic bronchitis was made when a history was given of daily cough with sputum which lasted for three months in at least two consecutive years.
RADIOLOGICAL A pair of postero-anterior inspirationexpiration films were taken with the cassette in a fixed position so that the bottom of the film was the same distance from the floor in both radiographs. This procedure was carried out by a specially trained radiographer, who instructed the patient to take a deep breath in and hold it while the first radiograph was taken; the patient then exhaled fully and sustained full expiration until the second radiograph was taken. A lateral view and bilateral multisection tomograms were also taken, the latter to define large areas with vessel loss.

All the radiographs were examined without knowledge of the clinical, physiological, or surgical findings. Certain observations and measurements were recorded on a pro forma. Details of the methods of making these observations and measurements together with normal values where appropriate are given in the Appendix. The main points noted were the following:

1. The diaphragm; whether normal, low or flat: the range of movement of the top of each dome

2. The heart size; whether normal, large or narrow vertical

3. The main pulmonary trunk; whether normal or dilated

4. The hilar vessels; whether normal or large

5. The intrapulmonary vessels in each lung zone; whether normal, large or small and whether there appeared to be an actual loss of vessels

6. Crowding together of vessels, or displacement of an interlobar fissure away from a transradiant avascular area indicating compression of lung by a bulla: demarcation of a bulla by a line shadow was not especially noted

7. The size of the retrosternal space estimated from the lateral view.

Using the evidence collected in this way we divided our patients into three groups. Emphysema was said to be 'generalized' when the first two or all three of Simon's signs (Table in Appendix) were present. The presence of bullae was not essential for this diagnosis. 'Localized' emphysema was diagnosed when only the vascular features were present in the radiograph: it was said to be 'extensive' when at most the whole of one lobe of the lung was unaffected by the vascular changes; lesser degrees of severity were referred to simply as 'localized'.

PHYSIOLOGICAL Vital capacity (V.C.) and F.E.V.1 were recorded using a fast recording spirometer with a light bell (Bernstein, D'Silva, and Mendel, 1952) ; the results are given at ambient temperature and pressure.

Residual volume, functional residual capacity, and total lung capacity, (R.V., F.R.C., and T.L.C.) were measured by the closed-circuit helium dilution method (McMichael, 1939). The rebreathing was continued until equilibration was reached or up to 25 minutes.

The gas transter factor $\left(T_{L}\right)$ was measured at rest 
and during exercise by the steady state technique using carbon monoxide as the tracer gas and end tidal sampling for the estimation of 'alveolar' CO concentration (Bates, Boucot, and Dormer, 1955).

The predicted normal values of Bates and Christie (1964) for lung volumes and transfer factor according to age, sex, and height were used.

Arterial blood was sampled at rest. The $p \mathrm{H}$ and partial pressures of oxygen and carbon dioxide $\left(\mathrm{PaO}_{2}\right.$ and $\left.\mathrm{PaCO}_{2}\right)$ were estimated at $38^{\circ} \mathrm{C}$. using suitable electrodes (Foskett, 1968).

Predicted $\mathrm{PaCO}_{2}$ values were calculated according to the equation $\frac{11.5}{\text { F.E.V.1 }}+30.7 \mathrm{~mm}$. Hg (Burrows, Strauss, and Niden, 1965).

Regional ventilation and perfusion of the lungs were assessed using xenon-133 with a system of fixed scintillation counters sited externally over the upper, middle, and lower zones of the upright chest wall on either side both anteriorly and posteriorly. The apparatus and procedure have been fully described elsewhere (Mannell, Prime, and Smith, 1966).

Briefly, the share of the counts summated anteriorly and posteriorly in each lung region is recorded after an intravenous injection of xenon-133 in saline during breathholding and reflects the regional perfusion ( $Q$ index). During a subsequent rebreathing procedure with xenon-133 in air from a closed circuit, the evenness of gas mixing within each region is calculated from the wash-in curve using the dynamic distribution index (D.D.I.) described by Bentivoglio, Beerel, Stewart, Bryan, Ball, and Bates (1963).

The D.D.I. in each region is not dependent on even mixing in other regions in an individual patient, and the values in different patients can be compared. The $Q$ index in each region is the ratio of the share of the total counts 'seen' in a particular region of the lung to its volume and is therefore influenced by the perfusion of other regions.

Normal values for the $\mathrm{Q}$ index were reported by Mannell et al. (1966) based on their own findings and those of Ball, Stewart, Newsham, and Bates (1962). Normal values for D.D.I. given by Bentivoglio et al. (1963) have been used in this study for purposes of comparison.

\section{RESULTS}

SYMPTOMS AND RADIOLOGICAL APPEARANCE The grades of breathlessness and the presence or absence of chronic bronchitis as judged from the answers given to the Medical Research Council questionnaire are shown in Table I. These are grouped according to the extent of the emphysema depicted radiologically. It can be seen that all the 22 patients with generalized emphysema were severely disabled by breathlessness on exertion. Nine of the 13 whose emphysema was extensive but localized were similarly severely breathless (grades 4 and 5) and nine of the 14 with less $\underset{\bar{N}}{\vec{F}}$ extensive localized disease. Although the pro- $\overline{0}$ portion of bronchitis in the generalized and other듬

T A B L E I

GRADES OF BREATHLESSNESS FOUND IN 49 PATIENTS WITH EMPHYSEMA OF DIFFERING EXTENT, 31 OF WHOM $U$ HAD CHRONIC BRONCHITIS (E \& B) AND 18 HAD NOT (E) $\overrightarrow{0}$

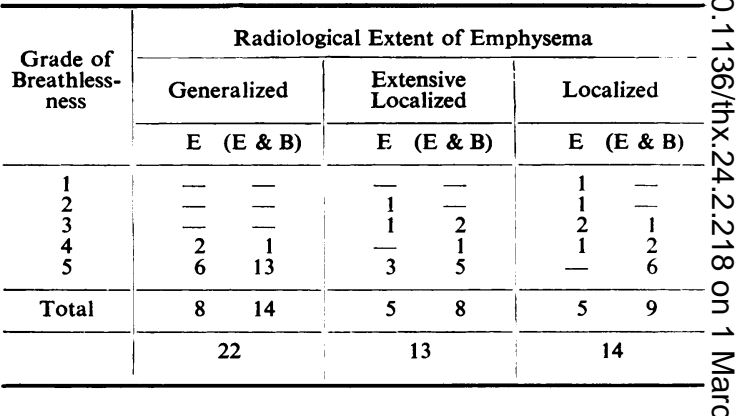

groups is essentially similar, it should be noted ${ }^{2}$ that of the very breathless patients in the localized group all but one had chronic bronchitis.

T A B L E I I

LUNG FUNCTION TESTS ACCORDING TO EXTENT OF EMPHYSEMA SHOWN RADIOLOGICALLY

\begin{tabular}{|c|c|c|c|c|}
\hline & & \multicolumn{3}{|c|}{ Extent of Emphysema } \\
\hline & & $\begin{array}{c}\text { Generalized } \\
n=22\end{array}$ & $\begin{array}{c}\begin{array}{c}\text { Extensive } \\
\text { Localized } \\
\mathbf{n}=13\end{array} \\
\end{array}$ & $\begin{array}{c}\text { Localized } \\
n=14\end{array}$ \\
\hline F.E.V.1 (ml.) & $\cdots$ & $\begin{array}{c}611 \pm 243 \\
(300-1,050)\end{array}$ & $\begin{array}{l}885 \pm 1,367 \\
(350-2,000)\end{array}$ & $\begin{array}{c}1,079 \div 64 \\
(500-2,300)\end{array}$ \\
\hline V.C. (1.) & . & $\begin{array}{l}2 \cdot 20 \pm 0.67 \\
(1 \cdot 20-3 \cdot 60)\end{array}$ & $\begin{array}{c}3 \cdot 04 \pm 0.991 \\
(1 \cdot 80-4 \cdot 30)\end{array}$ & $\begin{array}{l}3 \cdot 33 \pm 0 \cdot 09^{2} \\
(2 \cdot 20-4 \cdot 70)\end{array}$ \\
\hline$\%$ Predicted V.C. & . & $\begin{array}{c}53 \cdot 8 \pm 14 \cdot 2 \\
(32-89)\end{array}$ & $\begin{array}{c}69 \cdot 3 \pm 17 \cdot 8^{1} \\
(48-100)\end{array}$ & $\begin{array}{c}78 \cdot 9 \pm 14 \cdot 1^{2} \\
(59-106)\end{array}$ \\
\hline R.V./T.L.C. $\times 100$ & $\cdots$ & $\begin{array}{l}69 \cdot 7 \pm 10 \cdot 5 \\
(48 \cdot 0-82 \cdot 5)\end{array}$ & $\begin{array}{l}59 \cdot 2 \pm 10 \cdot 5^{1} \\
(38 \cdot 0-73 \cdot 0)\end{array}$ & $\begin{array}{c}53 \cdot 1 \pm 10 \cdot 7 \\
(38 \cdot 0-72 \cdot 5)\end{array}$ \\
\hline F.R.C. (1.) & $\cdots$ & $\begin{array}{l}6 \cdot 11 \pm 1 \cdot 83 \\
(3 \cdot 11-9 \cdot 80)\end{array}$ & $\begin{array}{l}5 \cdot 58 \pm 1 \cdot 18 \\
(4 \cdot 41-6 \cdot 87)\end{array}$ & $\begin{array}{l}5 \cdot 26 \pm 1 \cdot 191 \\
(3 \cdot 32-7 \cdot 66)\end{array}$ \\
\hline$\%$ Predicted F.R.C. & $\cdots$ & $\begin{array}{c}166 \cdot 8 \pm 41 \cdot 0 \\
(107-231)\end{array}$ & $\begin{array}{c}145 \cdot 8 \pm 27 \cdot 1 \\
(110-194)\end{array}$ & $\begin{array}{c}127 \cdot 4 \pm 34 \cdot 21 \\
(96-220)\end{array}$ \\
\hline T.L.C. (1.) & $\cdots$ & $\begin{array}{l}7 \cdot 52 \pm 1 \cdot 99 \\
(4 \cdot 16-11 \cdot 8)\end{array}$ & $\begin{array}{c}7 \cdot 40 \pm 1 \cdot 16 \\
(6 \cdot 61-10 \cdot 15)\end{array}$ & $\begin{array}{l}7 \cdot 06 \pm 1 \cdot 54 \\
(5 \cdot 14-9 \cdot 06)\end{array}$ \\
\hline$\%$ Predicted T.L.C. & & $\begin{array}{c}119 \cdot 3 \pm 24 \cdot 2 \\
(71-162)\end{array}$ & $\begin{array}{c}115 \cdot 0 \pm 16 \cdot 60 \\
(93-145)\end{array}$ & $\begin{array}{c}114 \cdot 1 \pm 20 \cdot 2 \\
(87-153)\end{array}$ \\
\hline $\begin{array}{c}\mathrm{T}_{\mathrm{LCo}}(\mathrm{ml} . / \mathrm{min} . / \\
\mathrm{mm} . \mathrm{Hg})\end{array}$ & $\cdots$ & $\begin{array}{l}6 \cdot 5 \pm 1 \cdot 96 \\
(3 \cdot 0-12 \cdot 6)\end{array}$ & $\begin{array}{l}8 \cdot 6 \pm 3 \cdot 05 \\
(4 \cdot 9-12 \cdot 6)\end{array}$ & $\begin{array}{l}8 \cdot 8 \pm 2 \cdot 12 \\
(7 \cdot 1-11 \cdot 3)\end{array}$ \\
\hline $\mathrm{PaO}_{2}$ (rest) (mm. $\mathrm{H}$ & $\mathrm{Hg})$ & $\begin{array}{c}75 \cdot 3 \pm 12 \cdot 53 \\
(53-100)\end{array}$ & $\begin{array}{c}89 \cdot 1 \pm 6 \cdot 6^{1} \\
(75-99)\end{array}$ & $\begin{array}{l}85 \cdot 1 \pm 7 \cdot 25^{2} \\
(740-98 \cdot 5)\end{array}$ \\
\hline $\mathrm{PaCO}_{2}$ (rest) (mm. H & $\mathrm{Hg})$ & $\begin{array}{l}45 \cdot 7 \pm 8 \cdot 3 \\
(32 \cdot 5-64)\end{array}$ & $\begin{array}{c}40 \cdot 9 \pm 6 \cdot 1 \\
(31-46)\end{array}$ & $\begin{array}{c}41 \cdot 7 \pm 5 \cdot 7 \\
(33-56)\end{array}$ \\
\hline
\end{tabular}

${ }^{1}$ Significantly different $(\mathbf{P}=\mathbf{0 . 0 1 )}$ from patients with generalized emphysema.

${ }^{2}$ Highly significantly different $(P=0.001)$ from patients with generalized emphysema.

The figures shown are the mean \pm the standard deviation of the mean.

The range of values in each group is in parentheses. 
TOTAL LUNG FUNCTION AND RADIOLOGICAL APPEARANCE The results of the lung function tests of the emphysematous patients are shown in Table II. They have been grouped according to the radiological extent of their emphysema. The vital capacity, percentage of the predicted vital capacity, R.V./T.L.C. and resting arterial oxygen tension are significantly worse in the 'generalized' group than they are in the other two groups. The difference between the means in the extensive localized and localized groups was in no instance significant, but there was a shift towards normal in all the values as the extent of the emphysema diminished.

All patients with generalized emphysema had severe airways obstruction (F.E.V.1 $<1,100 \mathrm{ml}$.) and a low transfer factor. In each of the extensive localized and localized groups there are two and three patients respectively whose F.E.V.. $\cdot_{1}$ was nearly or above 2 litres and whose V.C. was 4 litres. There was a tendency for lung function to be worse in the bronchitic patients but this was not significant except in the case of PacO2. Those with bronchitis had a mean Pacoz of $45 \cdot 2 \pm 8 \cdot 85$ $\mathrm{mm}$. $\mathrm{Hg}$ and those without a productive cough one of $39.4 \pm 4.65 \mathrm{~mm}$. $\mathrm{Hg}(\mathrm{P}=001)$.

To elucidate still further the effect of bronchitis on these emphysematous patients and to describe any differences in $\mathrm{PaCO}_{2}$ which were not dependent solely on airways obstruction the deviations from the predicted $\mathrm{PaCO}_{2}$ values using the F.E.V.1 were calculated in the groups of emphysematous patients, further divided into those with and without bronchitis. The results are shown in Table III.

T A B L E I I I

DEVIATIONS OF $\mathrm{PaCO}_{2}$ FROM PREDICTED VALUES IN GROUPS OF PATIENTS ACCORDING TO EXTENT OF EMPHYSEMA SEEN RADIOLOGICALLY AND PRESENCE OR ABSENCE OF CHRONIC BRONCHITIS

\begin{tabular}{|c|c|c|c|}
\hline \multirow{2}{*}{$\begin{array}{l}\text { Extent of } \\
\text { Emphysema }\end{array}$} & \multicolumn{3}{|c|}{ Deviation of $\mathrm{PaCO}_{2}$} \\
\hline & $\begin{array}{l}\text { Total Group } \\
\text { with or without } \\
\text { Bronchitis }\end{array}$ & $\begin{array}{c}\text { With } \\
\text { Bronchitis }\end{array}$ & $\begin{array}{l}\text { Without } \\
\text { Bronchitis }\end{array}$ \\
\hline $\begin{array}{l}\text { Generalized. . } \\
\text { Extensive }\end{array}$ & $-9 \cdot 1 \pm 10 \cdot 09$ & $-4 \cdot 7 \pm 7 \cdot 91^{1}$ & $-16 \cdot 4 \pm 11 \cdot 42^{1}$ \\
\hline $\begin{array}{c}\text { localized } \ldots \\
\text { Localized } \ldots\end{array}$ & $\begin{array}{l}-8.9 \pm 8 \cdot 14 \\
-3 \cdot 2 \pm 8.95\end{array}$ & $\begin{array}{l}-9 \cdot 2 \pm 10 \cdot 12 \\
-3 \cdot 3 \pm 7 \cdot 45\end{array}$ & $\begin{array}{l}-8 \cdot 4 \pm 4.43 \\
-2.9 \pm 7.27\end{array}$ \\
\hline
\end{tabular}

' Significantly different $(P=0 \cdot 05)$.

The figures shown are the mean \pm the standard deviation of the mean.

The $\mathrm{PaCO}_{2}$ is lower than predicted in all three groups and lowest in the generalized and extensive localized group, but there was no significant difference between the groups according to the radiological extent of the emphysema. The only significant effect of bronchitis was seen in the generalized emphysematous patients whose $\mathrm{PaCO}_{2}$ values deviated less from predicted if bronchitis was present. In the seven patients who had chronic obstructive bronchitis without radiological evidence of emphysema, the deviation from the predicted $\mathrm{PaCO} 2$ was $+3 \cdot 6 \pm 4 \cdot 3 \mathrm{~mm}$. $\mathrm{Hg}$.

INDIVIDUAL RADIOLOGICAL AND PHYSIOLOGICAL ASSOCIATIONS

Shape and level of diaphragm The diaphragm was normally curved in outline in 15 of the 49 emphysematous patients studied; in 28, the diaphragm was flat, and 21 patients with generalized emphysema were in this group. Six others, with only one flat hemidiaphragm, are not considered further. In the remaining 43 patients the level was low in 26 (Table IV). The effects of com-

\section{T A B L E I V}

STATISTICAL DATA RELATING SHAPE AND LEVEL OF DIAPHRAGM SHOWN RADIOLOGICALLY TO LUNG
VOLUMES (MEANS AND STANDARD DEVIATIONS IN
TABLE AND SIGNIFICANCE LEVES BELOW) TABLE AND SIGNIFICANCE LEVELS BELOW

\begin{tabular}{|c|c|c|c|c|}
\hline & \multicolumn{4}{|c|}{ Diaphragm Shape and Level } \\
\hline & $\begin{array}{l}\text { Flat and } \\
\text { Low (1) }\end{array}$ & $\begin{array}{c}\text { Flat and } \\
\text { Normal (2) }\end{array}$ & $\begin{array}{c}\text { Curved and } \\
\text { Low (3) }\end{array}$ & $\begin{array}{l}\text { Curved and } \\
\text { Normal (4) }\end{array}$ \\
\hline No. of patients & 16 & 12 & 8 & 7 \\
\hline $\begin{array}{l}\% \text { Predicted } \\
\text { F.R.C. } \\
\% \text { Predicted } \\
\text { T.L.C. } \\
\text { R.V./T.L.C. \% }\end{array}$ & $\begin{array}{r}171 \cdot 0 \pm 44 \cdot 3 \\
126 \cdot 1 \pm 23 \cdot 3 \\
71 \cdot 4 \pm 10 \cdot 6\end{array}$ & $\begin{array}{r}132 \cdot 1 \pm 35 \cdot 5 \\
102 \cdot 2 \pm 20 \cdot 0 \\
60 \cdot 1 \pm 11 \cdot 1\end{array}$ & $\begin{array}{c}168 \cdot 6 \pm 35 \cdot 9 \\
127 \cdot 7 \pm 20 \cdot 7 \\
60 \cdot 1 \pm 9 \cdot 1\end{array}$ & $\begin{array}{r}119 \cdot 7 \pm 13 \cdot 9 \\
105 \cdot 8 \pm 14 \cdot 7 \\
49 \cdot 3 \pm 10 \cdot 8\end{array}$ \\
\hline
\end{tabular}

No significant difference between 1 and 3 or 2 and 4 for any volume. $\mathbf{P}=0.01$ between 1 and 2 for $\%$ T.L.C.

$P=0.001$ between 1 and 4 , and 3 and 4 for $\%$ F.R.C.

between 1 and 4 for R.V./T.L.C. \%

binations of normal and abnormal level and shape of the diaphragm on the percentage predicted F.R.C. and T.L.C. and the R.V./T.L.C. ratio are indicated. Patients with low diaphragms had a significantly higher F.R.C. and T.L.C. than those with normal diaphragms. The effect of level on the R.V./T.L.C. ratio was not significant. There was no significant difference between the volumes in patients with flat diaphragms and those in whom it was curved.

The percentage of those who had a T.L.C. within the normal range was $37.5 \%$ when the diaphragm was flat and low, $87.5 \%$ when curved and at the normal level, $75 \%$ when flat and at the normal level, and $37 \%$ when curved and low. In other words, the volume of air in the chest at maximal inspiration was not always increased when the diaphragm was flat and low or when it was curved and low but it was so in the majority of patients. Most of the patients with the diaphragm at the normal level, whether flat or curved, had a total lung capacity within normal limits. 
Dimensions of retrosternal translucency The mean values for F.R.C. and T.L.C. as a percentage of the expected values and the ratio of the R.V./ T.L.C. were not significantly different in patients who had a retrosternal space less than $3 \mathrm{~cm}$. deep from those in whom it was more than $3 \mathrm{~cm}$.

Diaphragm movement Thirty-two out of the 36 patients whose diaphragm moved poorly (i.e., right plus left less than $6 \mathrm{~cm}$.) had an F.E.V.1 of less than 1 litre. There were also nine patients whose combined diaphragm movement was more than the average normal of $6 \mathrm{~cm}$., but only two of these had an F.E.V.1 of more than 2 litres. The vital capacity was similarly affected: it was below 2 litres in all 36 patients with poor diaphragm movement and above 3 litres in the nine
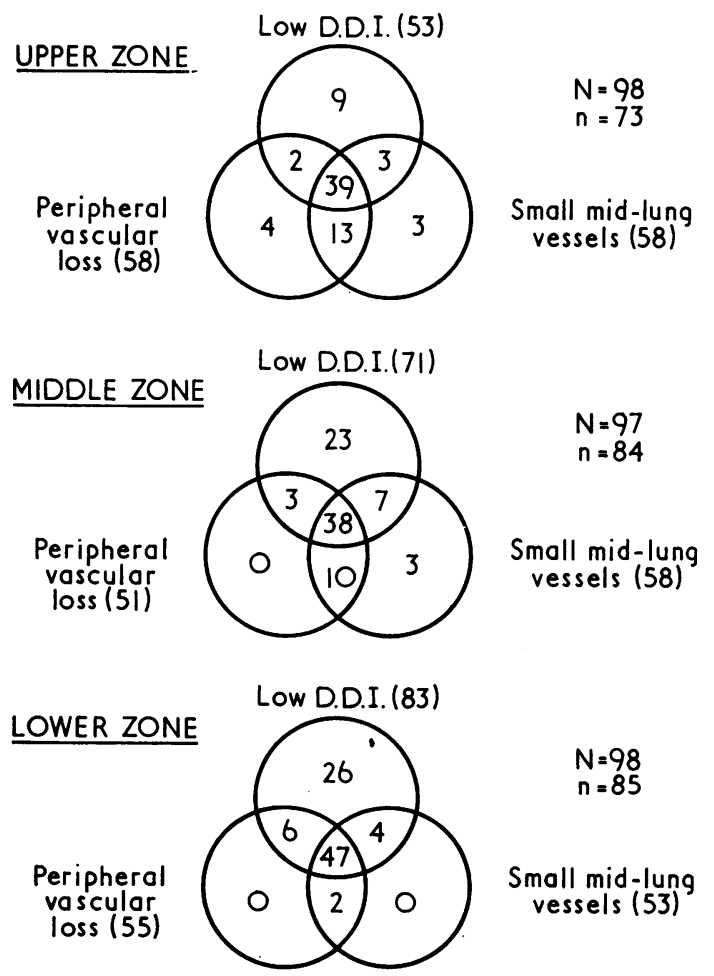

FIG. 1. Venn diagram showing incidence and distribution of radiological vascular abnormalities and poor intrapulmonary mixing (low D.D.I.) in emphysematous patients and the relationship between them. $N=$ total number of zones; $n=$ number of zones with some abnormality. The numbers in parentheses beside each circle denote the number of zones showing the abnormality which pertains to that circle.

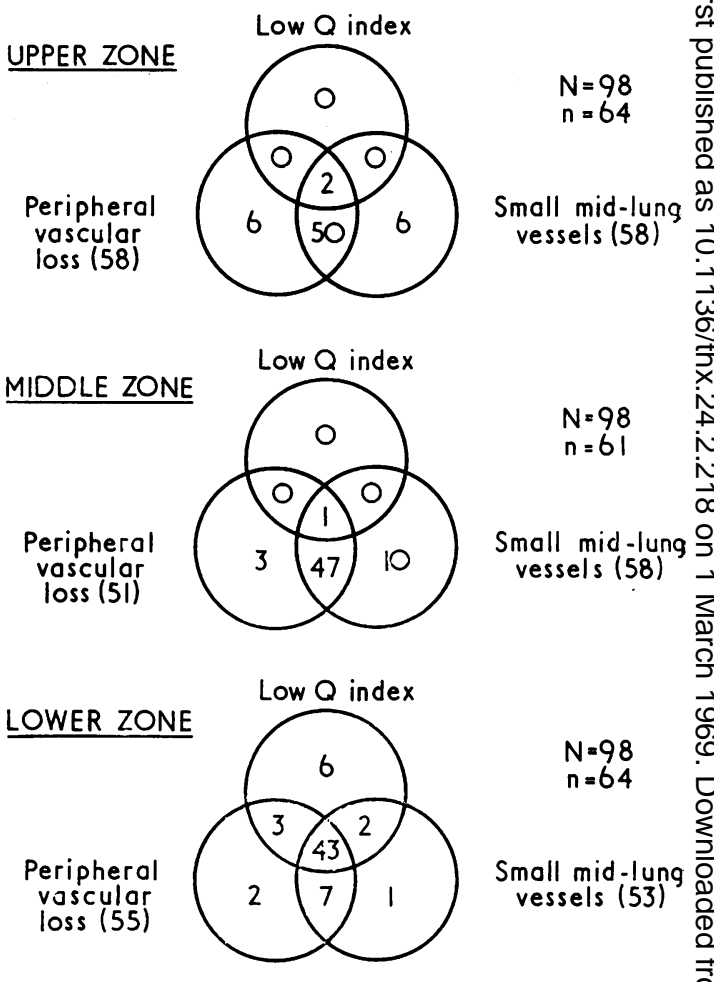

FIG. 2. Venn diagram showing incidence and distribution of radiological vascular abnormalities and poor blood flow (low $Q$ index) in emphysematous patients and the relation-0 ship between them. $N, n$ and numbers in parentheses are as shown in Figure 1.

with good movement. All the patients witho generalized emphysema had poor diaphragm? movement.

Regional pulmonary vessel size, peripheralo vascular shadows, regional blood-flow, and regional ventilation Two sets of Venn diagramso (School Mathematics Project, 1965) are shown in Figs 1 and 2, which indicate the frequency 0 and distribution of vascular abnormalities in the $N$ radiographs of 49 emphysematous patients. They N also show the extent to which they coincide witho poor regional ventilation (low D.D.I.) and blood flow (low $Q$ index) obtained from the radioactive xenon studies.

Each circle represents an abnormality and when 0 the circles overlap the abnormalities are shared ${ }^{\circ}$ in a region. The number contained in an over- $\mathbb{D}$ lapping section indicates the number of radio- $\overrightarrow{\mathbb{D}}$ graphic zones having two or all three abnormali- $\frac{\circ}{\sigma}$ ties at the same time. For example, in Fig. 1 in 
the upper zones of 53 patients, 39 zones had a low D.D.I., small lung vessels, and peripheral vascular loss; whereas 13 upper bones had small mid-lung vessels and peripheral vascular loss only. Thus $39 / 52$, i.e., $75 \%$ of zones with both vascular abnormalities, showed poor intrapulmonary mixing.

It is evident from Fig. 1 that when there are small lung vessels and evidence of peripheral vascular loss in a zone, the D.D.I. is low (showing the presence of poor intrapulmonary mixing) in $75 \%, 79 \%$, and $96 \%$ of instances in the upper, middle, and lower regions respectively (average $83 \%)$. The $\mathrm{Q}$ index is below the normal limits in these regions in $4 \%, 2 \%$, and $80 \%$ of instances (Fig. 2). The relationship between regional ventilation, regional blood flow, and regional vascular abnormalities was not modified by the presence of bronchitis in the emphysematous patients.

Figure 3 shows diagrammatically a comparison between the observed vascular pattern and poor intrapulmonary mixing. Emphysematous patients with bronchitis are considered separately from those without bronchitis; the seven patients with chronic obstructive bronchitis without gross emphysema are included in this diagram. Radiographic zones with normal mid-lung vessels and no vascular loss are depicted separately from those zones with vascular abnormalities. With normal lung vessels and no evidence of vascular loss, there is a higher incidence of poor intrapulmonary mixing in emphysematous patients with bronchitis $(29 \%, 80 \%$, and $79 \%$ in the upper, middle, and lower zones respectively) than in emphysematous patients with no bronchitis $(20 \%, 30 \%$, and $47 \%$ in respective zones). The difference is most marked in the middle and lower zones.

The seven patients with chronic obstructive bronchitis, who by definition had normal lung vessels and no vascular loss radiologically, had poor intrapulmonary mixing in $25 \%, 75 \%$, and $81 \%$ of the upper, middle, and lower zones (see Fig. 3). These figures suggest that, in the emphysematous groups, the high incidence of poor ventilation in the middle and lower regions even with a normal vascular pattern was due to chronic bronchitis.

The $\mathrm{Q}$ indices were also found to be reduced in bronchitic patients in the lower zones in $69 \%$ of instances when the vessels were radiologically normal, but this reduction in blood flow associated with bronchitis is less striking in the empyhsematous patients than is the impairment of ventilation.

Relationship between regional and total lung function In order to compare the regional distribution of impaired function with total function a coding was used as explained in the legend of Table V. The numbers of patients affected in the groups derived are shown. Table VI shows the values of total lung function tests in these coded groups. It is evident that when one or both of the lower regions have normal intrapulmonary mixing, as shown by the D.D.I., the F.E.V. ${ }_{1}$ and $\mathrm{PaO}_{2}$ at rest are significantly higher than in those patients who have both lower regions with poor mixing. There is no other significant difference

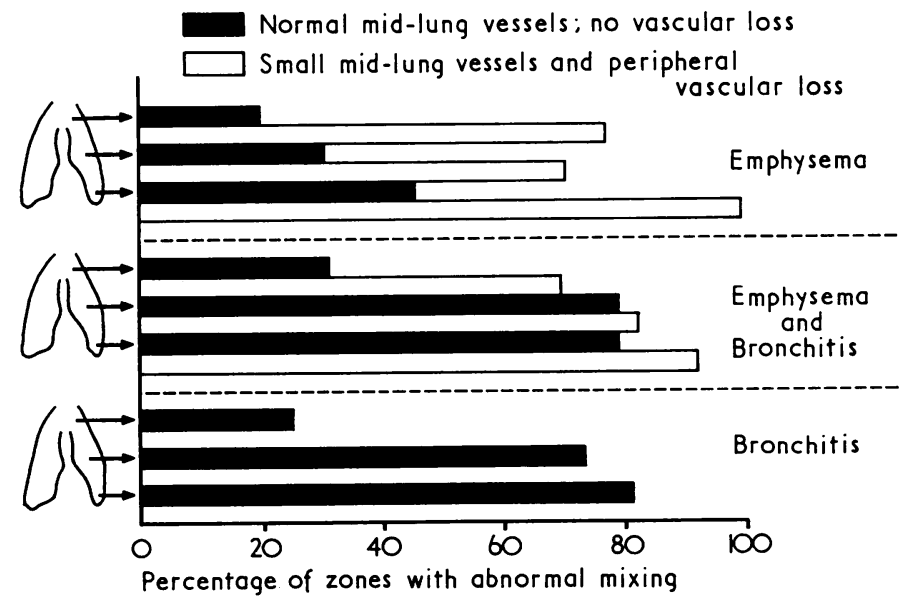

FIG. 3. Percentage incidence of abnormally poor intrapulmonary mixing in patients as described in text, considering normal and abnormal pattern separately in individual zones. 
T A B L E V

DISTRIBUTION OF IMPAIRMENT IN REGIONAL FUNCTION IN PATIENTS WITH EMPHYSEMA

\begin{tabular}{|c|c|c|}
\hline Regional Function Impairment & $\begin{array}{l}\text { No. of } \\
\text { Patients }\end{array}$ & Coding \\
\hline 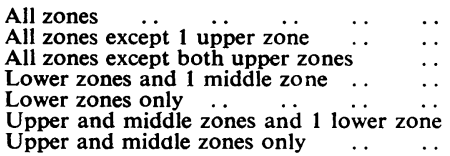 & $\begin{array}{r}8 \\
5 \\
13 \\
5 \\
9 \\
8 \\
2\end{array}$ & $\begin{array}{l}222 \\
122 \\
022 \\
012 \\
002 \\
221 \\
220\end{array}$ \\
\hline
\end{tabular}

${ }^{1}$ The first, second, and third number of the coding refers to the number of upper, middle, and lower regions respectively of the lungs with a lower D.D.I. than normal.

\section{T A B L E V I}

TOTAL LUNG FUNCTION TESTS IN GROUPS OF PATIENTS WITH EMPHYSEMA ACCORDING TO IMPAIR MENT IN REGIONAL LUNG FUNCTION. MEAN VALUES \pm STAN DARD DEVIATION OF MEAN RANGE OF VAL̈UES IN PARENTHESES

\begin{tabular}{|c|c|c|c|c|}
\hline \multirow{2}{*}{$\begin{array}{c}\text { Total } \\
\text { Lung } \\
\text { Function } \\
\text { Tests }\end{array}$} & \multicolumn{4}{|c|}{ Groups according to Regional Impairment of Function ${ }^{1}$} \\
\hline & $\begin{array}{l}222 \\
122\end{array}$ & 022 & $\begin{array}{l}221 \\
220\end{array}$ & $\begin{array}{l}012 \\
002\end{array}$ \\
\hline $\begin{array}{l}\text { F.E.V } \\
\left(\mathrm{ml}^{1}\right)^{1}\end{array}$ & $\begin{array}{l}661 \pm 212 \cdot 3 \\
(250-2000)\end{array}$ & $\begin{array}{l}715 \pm 205 \cdot 7 \\
(400-1050)\end{array}$ & $\begin{array}{l}1230 \pm 252 \cdot 0 \\
(350-2300)\end{array}$ & $\begin{array}{l}817 \pm 411 \cdot 1 \\
(300-1100)\end{array}$ \\
\hline V.C. (I.) & $\begin{array}{c}2 \cdot 58+1 \cdot 014 \\
(1 \cdot 2-4 \cdot 5)\end{array}$ & $\begin{array}{c}2 \cdot 61 \pm 0.762 \\
(1.4-3.8)\end{array}$ & $\begin{array}{c}3.24 \pm 1 \cdot 180 \\
(1 \cdot 6-4 \cdot 7)\end{array}$ & $\begin{array}{c}2 \cdot 65 \pm 0 \cdot 805 \\
(1 \cdot 4-4 \cdot 4)\end{array}$ \\
\hline F.R.C. (1.) & $\begin{array}{l}6 \cdot 01 \pm 1 \cdot 44 \\
(3 \cdot 11-7 \cdot 66)\end{array}$ & $\begin{array}{l}5 \cdot 26 \pm 1 \cdot 50 \\
(3 \cdot 32-8 \cdot 40)\end{array}$ & $\begin{array}{l}5.90 \pm 1 \cdot 35 \\
(4.05-7.80)\end{array}$ & $\begin{array}{l}5 \cdot 34 \pm 1 \cdot 86 \\
(3 \cdot 08-9 \cdot 80)\end{array}$ \\
\hline $\begin{array}{l}\text { R.V./T.L.C. } \\
(\%)\end{array}$ & $\begin{array}{c}64 \cdot 6 \pm 12 \cdot 49 \\
(38-79)\end{array}$ & $\begin{array}{c}60 \cdot 4 \pm 11 \cdot 66 \\
(45-80)\end{array}$ & $\begin{array}{c}59 \cdot 0 \pm 14 \cdot 39 \\
(41-82)\end{array}$ & $\begin{array}{c}61 \cdot 4 \pm 14 \cdot 25 \\
(38-77)\end{array}$ \\
\hline $\begin{array}{l}\text { DLco, rest } \\
\text { (ml. CO/ } \\
\text { min./mm. } \\
\text { Hg) }\end{array}$ & $\begin{array}{l}6 \cdot 64 \pm 2 \cdot 97 \\
(3 \cdot 0-11 \cdot 4)\end{array}$ & $\begin{array}{l}7 \cdot 43 \pm 1 \cdot 85 \\
(4 \cdot 6-11 \cdot 8)\end{array}$ & $\begin{array}{l}8 \cdot 76 \pm 2 \cdot 45 \\
(5 \cdot 7-12 \cdot 6)\end{array}$ & $\begin{array}{l}8 \cdot 56 \pm 3 \cdot 13 \\
(4 \cdot 7-13 \cdot 5)\end{array}$ \\
\hline $\begin{array}{l}\text { DLco, exer- } \\
\text { cise (ml. } \\
\mathrm{CO} / \mathrm{min} . / \\
\mathrm{mm} . \mathrm{Hg} \text { ) }\end{array}$ & $\begin{array}{c}10 \cdot 9 \\
(8 \cdot 4-15 \cdot 2)\end{array}$ & $\begin{array}{c}11 \cdot 7 \\
(4 \cdot 5-18 \cdot 2)\end{array}$ & $\begin{array}{c}13 \cdot 4 \\
(5 \cdot 8-24 \cdot 2)\end{array}$ & $\begin{array}{c}12 \cdot 4 \\
(5 \cdot 9-19 \cdot 8)\end{array}$ \\
\hline $\begin{array}{l}\mathrm{PaO}_{2}, \text { rest } \\
(\mathrm{mm} . \mathrm{Hg})^{2}\end{array}$ & $\begin{array}{r}77 \cdot 6 \pm 16 \cdot 09 \\
(53 \cdot 0-96 \cdot 5)\end{array}$ & $\begin{array}{r}79 \cdot 1 \pm 10 \cdot 67 \\
(72 \cdot 5-99 \cdot 5)\end{array}$ & $\begin{array}{l}88 \cdot 9 \pm 9 \cdot 20 \\
(72 \cdot 0-98 \cdot 5)\end{array}$ & $\begin{array}{r}79 \cdot 4 \pm 10 \cdot 54 \\
(64 \cdot 0-99 \cdot 0)\end{array}$ \\
\hline $\begin{array}{r}\mathrm{PaCO}_{2}, \text { rest } \\
(\mathrm{mm} . \mathrm{Hg})\end{array}$ & $\begin{array}{l}43 \cdot 7 \pm 9 \cdot 83 \\
(32 \cdot 5-62 \cdot 0)\end{array}$ & $\begin{array}{l}45 \cdot 5 \pm 9 \cdot 06 \\
(33 \cdot 0-62 \cdot 0)\end{array}$ & $\begin{array}{l}43 \cdot 4 \pm 6 \cdot 35 \\
(36 \cdot 0-56 \cdot 0)\end{array}$ & $\begin{array}{l}41 \cdot 8-9 \cdot 29 \\
(33 \cdot 0-56 \cdot 0)\end{array}$ \\
\hline & $\begin{array}{l}{ }^{1} \mathrm{P}>0.001 \\
{ }^{2} \mathrm{P}>0.05\end{array}$ & 221 & 2 and $\begin{array}{l}012 \\
002\end{array}$ & \\
\hline
\end{tabular}

between these coded groups even when the percentage predicted values are considered.

\section{DISCUSSION}

Our patients were divided into two broad categories from the radiographs: (a) generalized widespread emphysema with evidence of 'excess air in the lungs' and cardiovascular changes, and $(b)$ localized emphysema. In the latter the cardiovascular changes may be confined to three radiographic zones or less, or may be more extensive but still localized in that a whole radiographic zone of lung appears to have normal vessels. In many of the examples with localized disease especially when the lesions were confined to the upper half of the lungs, there was also radiologica evidence of 'excess air in the thorax' (see Appen $\frac{\bar{C}}{\bar{T}}$ dix). From the physiological point of view, thes $\mathbb{8}$ two broad categories correspond well with the functional disturbance we have observed. When however, small groups of patients are considered $P$ some salient points emerge. In every case of 'generalized' emphysema there was severe airway obstruction with consequent distortion of the्ट normal pattern of distribution of the subdivisions of lung volume, defective gas transfer, and severe physical disability. Not all patients with the radio logical appearances of 'localized' or 'extensiv $\overrightarrow{E 0}$ localized' emphysema had evidence of airways obstruction, nor were they all disabled by breath lessness. Five patients had little or no disabilit but had two, three or four lung zones with smal mid-lung vessels and peripheral vascular loss $\stackrel{5}{5}$ none of these had unilateral transradiancy of demarcated bullae as the sole change. The all had radiographic changes involving the upper and middle zones. There was no difference beo tween the appearances in these patients and others with similar radiographs but severe disability.

It appears to be useful to distinguish radio logically between the 'generalized' and 'localized forms of emphysema. Generally speaking, the physician is interested in the cause of his patient's symptoms. Since lung function may be little dis turbed when there are vascular changes in fous zones of the lung, but no other signs of emphy sema, severe functional changes in such patients cannot be due to emphysema alone, and are prob ably due to chronic bronchitis or some other cause of airways obstruction.

Burrows et al. (1966) showed that the deviation of the measured from the predicted $\mathrm{PaCO}_{2}$ in relaO tion to the level of the F.E.V..$_{1}$ was the best single test of the presence of anatomical emphysemao They found that the extent of the emphysema pathologically correlated well with the relativeos hypocapnia. It is therefore interesting to note than the patients we studied had on the average a rela N tive hypocapnia, and in those with generalized or extensive localized emphysema this was marked. Their figures support the assumption madet throughout this study that anatomical emphy sema was indeed present in our patients. Also the radiological extent of the emphysema is propor- -0 tional to the degree of relative hypocapnia. It isp also interesting that the effect of bronchitis was not discernible except in the group of patients withe generalized emphysema (see Table III). Chronic 
bronchitis has been shown to cause a relative hypercapnia. This has been used by Burrows et al. (1966) in the points of selection of patients with type $B$ airways obstruction. In the patients with generalized emphysema in this study there was more relative hypocapnia in those without bronchitis, as might be expected. Since even the patients with a productive cough in the generalized emphysema group had a relative hypocapnia, emphysema may well have been the main cause of their functional defect.

A possible explanation for differences in disability in patients with localized emphysema is the degree of compression, if any, which may be produced by distension of the emphysematous parts of the lung. We have not been able to verify this hypothesis. Fifteen of our patients had evidence of this, seven with generalized and eight with localized emphysema, and all but three of them were severely disabled (breathlessness grade $5)$; in four, the lower lobes were compressed. In severity of symptoms they were no different from the rest of the patients with otherwise comparable radiographs. Nor was there any systematic difference in blood gas concentrations to suggest that compression was causing more shunting of blood through poorly ventilated lung than in other similar patients. It appears that we cannot predict the effect of compression in a particular case.

We have found that although the total lung capacity is related to the level of the diaphragm, it is unrelated to its shape or to the size of the retrosternal space. We conclude that the radiological appearance of 'excess air in the thorax' is a purely descriptive term with no necessary connexion with the size of total lung capacity.

The apparent movement of the diaphragm, as we observed it, bore no simple or close relationship to the F.E.V..$_{1}$ or to the vital capacity. This is not surprising because even in normal persons the range of movement may be slight (Simon, 1969a). Since, unlike Wade and Gilson (1951), we made no volume measurements simultaneously with the radiographs, we were not able to compare subdivisions of vital capacity with diaphragm movement as they did.

For the radiological assessment of emphysema on a regional basis we are dependent mainly on the appearance and distribution of vascular shadows. Our findings show that there is a considerable degree of agreement between poor ventilation and deficiencies in the pulmonary vasculature, a point which will be discussed later. We have also shown that in a proportion of the cases where the vascular shadows are normal both ventilation and blood-flow may be seriously deranged, especially in bronchitic patients. This point is illustrated in Fig. 3, which shows how pronounced are the effects of chronic bronchitis on the function of the lower regions, and suggests that the main effect of bronchitis in the emphysematous patient depends upon the extent to which the lower regions are affected. If the emphysema is localized and involves only the upper and middle radiographic zones, then overall function may be quite good. However, in these patients if there is a history of chronic bronchitis, in $80 \%$ of cases there is poor function in the lower regions as well despite the normal appearance of the vessels: this poor function produces blood gas abnormalities and will accentuate the effects of the airways obstruction.

It has been shown that patients who have lower regions with normal intrapulmonary mixing have a significantly higher arterial oxygen tension than patients with other patterns of regional lung function (Table VI). This is probably simply a reflection of the volume of functioning lung tissue capable of gas exchange. It is the number of alveoli with low $\mathrm{V} / \mathrm{Q}$ ratios that will determine the degree of hypoxaemia of a patient with ventilation perfusion inequality and not necessarily the spatial distribution of these alveoli. However, as there are more and smaller alveoli with a larger surface area per unit volume in the lower regions than in the upper regions (Glazier, Hughes, Mahoney, Pain, and West, 1966), the normality of intrapulmonary mixing in the lower regions is of greater importance to overall gas exchange.

In this study we have found that the measurement of the regional blood flow was not closely related to changes in vessel size as shown in the radiograph. It was unusual for the $Q$ index to be abnormally low in the upper and middle regions. This is probably because the range of normal values is wide, and normally the blood flow in the upper regions of the upright lung can be very low. This, coupled with the fact that we are measuring a share of perfusion which is influenced by the perfusion of regions elsewhere in the lung, probably explains our findings. Bentivoglio et al. (1963) stated that in 26 of 32 patients with emphysema the perfusion indices agreed with the vessel changes but they did not specify the location of the regions where there was disagreement. In these data there is almost total disagreement (see Fig. 2) in the upper and middle zones between the $Q$ indices and small lung vessels. In zones with normal vascular shadows the $Q$ indices were also normal. 
We must stress that neither with the regional lung function studies nor by comparing the ventilation with the appearances of small mid-lung vessels on a radiograph are we measuring ventilation perfusion relationships. Millions of alveoli are present in one region and the observed ventilation of that region may well serve a different population of alveoli from the perfusion observed in the same region. The regional ventilation and perfusion cannot therefore be compared with one another in a meaningful fashion. The perfusion of a region of lung with small mid-lung vessels is not low because the vessels are small, as the size of the vessels is not necessarily related to the amount of blood passing through them. The emphysematous lung is known to have uneven ventilation and a relatively fixed ventilation perfusion imbalance (Jones, 1966). It is therefore under-perfused and under-ventilated and for these reasons there is remarkably little effect on the blood gases considering the amount of lung involved.

\section{APPENDIX}

\section{RADIOLOGICAL APPEARANCES}

The reproducibility of the opinions expressed by different observers for the radiological diagnosis of emphysema using the criteria proposed by Simon (1964) (see below) is certainly open to

\section{Criteria for the radiographic diagnosis of} emphysema (Simon, 1964)

1. Excess of air in lungs

Low flat diaphragm

Large retrosternal translucent area

2. Cardiovascular changes

Narrow vertical heart

Prominence of pulmonary trunk

Large hilar and small lung vessels

3. Bullae

A vascular transradiant area (vessel loss)

May be demarcated by a white line

May have no definite border

doubt; they have therefore been described in greater detail by Simon (1969a). Some measurements have been used to make these observations more objective and this may improve the agreement between observers. Normal values for these measurements are given below together with the other signs used.

\section{EXCESS OF AIR IN LUNGS}

Low flat diaphragm The diaphragm was considered to be low if, in the mid-lung field, the top of the right dome lay below the level of the inferio margin of the anterior end of the 6th rib. To define the shape of the diaphragm, a line was drawn from the cardiophrenic to the costophrenio angle and the curve of each dome was considere $\Phi$ to be flat if it was nowhere more than $1.5 \mathrm{~cm}_{\mathrm{c}}$ above this line.

Diaphragm movements The movement of each hemidiaphragm was measured as the change if the distance of the middle of the dome from the lower border of this film taken at inspiration an expiration. For the purposes of this paper move ment was considered to be limited when this dif tance measured $3 \mathrm{~cm}$. or less on either side; the total movement was the sum of the movements of both sides. Since this work was completed Simon has found that in $23 \%$ of 181 normal subz jects without evidence of airways obstruction the right hemidiaphragm moved less than $3 \mathrm{~cm}$. during this manœuvre (Simon, 1969b).

Retrosternal translucent area The depth of this area was measured from the internal surface of the sternum to the ascending aorta. It was cons sidered to be larger than normal if it was more than $3 \mathrm{~cm}$. The position of the lower margin of the retrosternal space is normally $7 \mathrm{~cm}$. or more above the horizontal level of the diaphragmati shadow seen on the lateral radiograph. Thi measurement is referred to as the 'downward ex? tension' of the space. The values given for these measurements are based on a review of the cases of Reid and Millard (1964) and many others wit pathological proof of grades 3 and 4 panacina emphysema, all of whom were found to have retrosternal translucent area more than $3 \mathrm{~cm}$. deep and extending to within $5 \mathrm{~cm}$. of the diag phragm.

In many patients the measuring points cannof be accurately defined on the lateral view film so this observation may be of uncertain value. It possible for a patient with localized emphyseman having a single large bulla in the upper lobe on one side, to have a large retrosternal space whict may also be seen in normal persons.

\section{CARDIOVASCULAR CHANGES}

The heart size Heart shadows measuring leșf than $11.5 \mathrm{~cm}$. in transverse diameter were clase sified as narrow. Few normal subjects have a hea as narrow as this whereas in widespreas generalized emphysema the heart is usually narro and vertical unless the patient is in heart failure or also has ischaemic heart disease. 
Main pulmonary trunk This was considered to be dilated when a moderate lateral convexity was present on the left heart border just below the aortic knuckle: it could not be assessed if the patient was rotated.

Hilar vessels The hilar arteries were not measured in all cases, but were large in patients with widespread emphysema. Normal values described by Abrams (personal communication) and Simon (1964) were used as standards for comparison.

Lung vessels beyond the hila In this study an effort was made to compare more normal vessels ('marker vessels') in one or more areas of the radiograph with others at a similar distance from the hilum in the lung. The 'marker vessels' can be identified with ease in 98 of 100 radiographs of patients with widespread emphysema (Simon, 1969a). Using this method, the mid-lung vessels were assessed for size and number in the upper, middle, and lower zones of each lung, and any peripheral vascular loss was noted. The distribution and extent of these changes were used to define the radiological extent of localized emphysema.

\section{REFERENCES}

Aslett, E. A., Hart, P. D'Arcy, and McMichael, J. (1939). The lung volume and its subdivisions in normal males. Proc. roy. Soc. B. $126,502$.

Ball, W. C., Jr., Stewart, P. B., Newsham, L. G. S., and Bates, D. V. (1962). Regional pulmonary function studied with Xenon ${ }^{133}$ J. clin. Invest., 41, 519.

Barnhard, H. J., Pierce, J. A., Joyce, J. W., and Bates, J. H. (1960) Roentgenographic determination of total lung capacity. Amer. $J$. Med., 28,51 .

Bates, D. V., Boucot, N. G., and Dormer, A. E. (1955). The pulmonary diffusing capacity in normal subjects. J. Physiol. (Lond.), 129, 237.

and Christie, R. V. (1964). Respiratory Function in Disease. Saunders, Philadelphia and London.

Bentivoglio, L. G., Beerel, F., Stewart, P. B., Bryan, A. C., Ball, W.C., Jr., and Bates, D. V. (1963). Studies of regional ventilation and perfusion in pulmonary emphysema using xenon ${ }^{133}$. Amer. Rev. resp. Dis., 88, 315.

Bernstein, L., D'Silva, J. L., and Mendel, D. (1952). The effect of the rate of breathing on the maximum breathing capacity determined with a new spirometer. Thorax, 7,255
Burrows, B., Fletcher, C. M., Heard, B. E., Jones, N. L., and Wootliff, J. S. (1966). The emphysematous and bronchial types of chronic airways obstruction. Lancet, 1, 830.

- Strauss, R. H., and Niden, A. H. (1965). Chronic obstructive lung disease, III. Interrelationships of pulmonary function data. Amer. Rev. resp. Dis., 91, 861 .

Ciba Guest Symposium Report (1959). Terminology, definitions, and classification of chronic pulmonary emphysema and related conditions. Thorax, 14, 286.

Fletcher, C. M., Hugh-Jones, P., McNicol, M. W., and Pride, N. B. (1963). The diagnosis of pulmonary emphysema in the presence of chronic bronchitis. Quart. J. Med., 32, 33.

Foskett, M. (1968). Laboratory Investigation of Pulmonary Function. Fellowship Dissertation, Institute of Science and Technology.

Glazier, J. B., Hughes, J. M. B., Maloney, J. E., Pain, M. C. P., and West, J. B. (1966). Decreasing alveolar size from apex to base in the upright lung. Lancet, $2,203$.

Hurtado, A., and Fray, W. W. (1933). Studies of total pulmonary capacity and its subdivisions. II. Correlation with physical and radiological measurements. J. clin. Invest., 12, 807.

Jones, N. L. (1966). Pulmonary gas exchange during exercise in patients with chronic airway obstruction. Clin. Sci., 31, 39.

Laws, J. W., and Heard, B. E. (1962). Emphysema and the chest film: a retrospective radiological and pathological study. Brit. J. Radiol., 35, 750.

McMichael, J. (1939). A rapid method of determining lung capacity. Clin. Sci., 4, 167

Mannell, T. M., Prime, F. J., and Smith, D. W. (1966). A practical method of using radioactive xenon for investigating regiona lung function. In Regional Lung Function. An International Symposium. Scand. J. resp. Dis., Suppl. 62, p. 41.

Medical Research Council (1960). Standardized questionaries on respiratory symptoms. Brit. med. J., 2, 1665.

(1965). Definition and classification of chronic bronchitis for clinical and epidemiological purposes. Lancet, 1, 775.

Nash, E. S., Briscoe, W. A., and Cournand, A. (1965). The relationship between clinical and physiological findings in chronic obstructive disease of the lungs. Progress in Research in Emphysema and Chronic Bronchitis. Vol. 2, p. 305. Ed. Mitchell, R. S. Karger, Basel and New York.

Reid, L., and Millard, F. J. C. (1964). Correlation between radiological diagnosis and structural lung changes in emphysema. Clin. Radiol., 15, 307.

_ and Simon, G. (1959). Pathological findings and radiological changes in chronic bronchitis and emphysema. Brit. J. Radiol., 32, 291.

School Mathematics Project (1965). Book 1, p. 25. Cambridge University Press, London.

Simon, G. (1964). Radiology and emphysema. Clin. Radiol., 15, 293.

- (1969a). Frontiers of Pulmonary Radiology. Ed. Simon, M. Saunders, Philadelphia (in press).

- (1969b). The range of movement of the diaphragm. Clin. Radiol. (in press).

Thurlbeck, W. M., Fraser, R. G., and Bates, D. V. (1965). The correlation between pulmonary structure and function in chronic bronchitis, emphysema and asthma. Progress in Research in Emphysema and Chronic Bronchitis. Vol. 2, p. 295. Ed. Mitchell, R. S. Karger, Basel and New York.

Wade, O. L. (1954). Movements of the thoracic cage and diaphragm in respiration. J. Physiol. (Lond.), 124, 193.

- and Gilson, J. C. (1951). The effect of posture on diaphragmatic movement and vital capacity in normal subjects with a note on spirometry as an aid in determining radiological chest volumes. Thorax, 6, 103 . 